\title{
Cigarette affordability in the Eastern Mediterranean Region
}

Miriam R.P. Gordon, ${ }^{1}$ Anne-Marie Perucic ${ }^{2}$ and Robert Angelo P. Totanes ${ }^{2}$

${ }^{1}$ World Health Organization Regional Office for the Eastern Mediterranean, Cairo, Egypt. ${ }^{2}$ World Health Organization, Geneva, Switzerland. (Correspondence to: Miriam R.P. Gordon: miriamrpgordon@gmail.com).

\begin{abstract}
Background: The World Health Organization Eastern Mediterranean Region is the only WHO region with increasing male prevalence of smoking tobacco products observed and predicted. There is no regional analysis of cigarette affordability in the literature.

Aims: This study aimed to compare the affordability of the cheapest, most sold and premium brands of cigarettes between countries of the Eastern Mediterranean Region (EMR) and countries in the rest of the world by income group in 2008 and 2018.

Methods: Affordability was defined as the percentage of GDP per capita needed to purchase 2000 cigarette sticks. A simple average and 95\% confidence interval of affordability was calculated by income group for EMR countries and for the rest of the world.

Results: Historically, the cheapest, most sold and premium brands of cigarettes have on average been more affordable in the EMR compared to the same brands in the rest of the world in every income group. This pattern persists despite some convergence between the affordability of cigarettes in the EMR and in countries in the rest of the world.

Conclusion: The historic and persisting higher affordability of cigarettes in the EMR relative to the rest of the world could offer an explanation to the tobacco prevalence trends in the region. Continued implementation of Article 6 of the WHO Framework Convention on Tobacco Control is needed.
\end{abstract}

Keywords: tobacco, economics, smoking, taxation

Citation: Gordon MRP; Perucic A-M; Totanes RAP. Cigarette affordability in the Eastern Mediterranean Region. East Mediterr Health J. 2020;26(1):556o. https://doi.org/10.26719/2020.26.1.55

Received: 31/10/19 accepted: 22/01/20

Copyright (c) World Health Organization (WHO) 2020. Open Access. Some rights reserved. This work is available under the CC BY-NC-SA 3.0 IGO license (https://creativecommons.org/licenses/by-nc-sa/3.o/igo).

\section{Introduction}

Currently, tobacco use claims the lives of 8 million people globally each year. This figure is likely to increase if tobacco control measures are not implemented or further strengthened (1). Tobacco use is an epidemic that places a higher burden on low- and middle-income countries, where $80 \%$ of tobacco users are located (2).

The World Health Organization (WHO) Eastern Mediterranean Region (EMR) consists of 22 Member States (Afghanistan, Bahrain, Djibouti, Egypt, Islamic Republic of Iran, Iraq, Jordan, Kuwait, Lebanon, Libya, Morocco, Oman, Pakistan, Palestine, Qatar, Saudi Arabia, Somalia, Sudan, Syrian Arab Republic, Tunisia, United Arab Emirates and Yemen), with a population of nearly 679 million people (3). The prevalence of use of smoking tobacco products (including but not limited to cigarettes and water pipes) by males aged 15 years or older is decreasing in all WHO regions apart from the EMR, where it continues to increase (4). In EMR countries, approximately $14 \%$ of the population aged 15 years or more are current cigarette smokers, with prevalence noticeably higher among males $(25 \%)$ when compared to females (2\%) (5).

The World Health Organization Framework Convention on Tobacco Control (WHO FCTC) and its implementation guidelines provide an evidence-based framework for governmental action to reduce tobacco use (6). Article 6 of the WHO FCTC outlines the "Price and tax measures to reduce the demand for tobacco" (6). Effective tobacco tax policies can significantly improve health and economic outcomes for individuals, households, and the country, especially in low-income settings (5,7-9). Evidence shows that raising tax on tobacco increases the real price of tobacco and reduces tobacco consumption (6). Approximately half of the impact of a price increase is on the prevalence of use and half is on the intensity of consumption among users (6). Therefore, taxation must increase prices more than any growth in average income occurring at the same time in order to prevent tobacco becoming more affordable (6).

Research has suggested that tobacco affordability benchmarks may be more effective than tax incidence benchmarks, since tax incidence benchmarks do not respond to changes in average income (10). Rising incomes may undermine pre-existing high levels of taxation unless tobacco taxes are raised in response to changes in income. This argument is particularly pertinent in the case of lower middle-income countries experiencing rapid economic growth (10). Previous research has shown that globally the most sold brand of cigarettes in countries are becoming less affordable in upper middle and high-income countries and more affordable in low and lower middle-income countries $(5,11,12)$. 
The EMR is the only WHO region with observed and predicted increases in the prevalence of the use of smoking tobacco among males aged 15 years or older (4). This research analyses the affordability of cigarettes in the EMR compared to the rest of the world to determine if there are systematic differences that could shed light on this prevalence trend. Furthermore, if there is a difference between affordability in the EMR and the rest of the world, there may be a pressing need to expedite implementation of Article 6 of the WHO FCTC.

\section{Methods}

\section{Objectives}

The aims of this research was to explore if trends in the affordability of cigarettes in the EMR differ significantly from the rest of the world, and if it is an influencing factor in the current and predicted increase in the prevalence of tobacco use among males in the EMR (4). In order to address this, the affordability of the cheapest, most sold and premium brands of cigarettes was compared between countries of the EMR and countries in the rest of the world by income group in 2008 and 2018.

This research also aimed to establish if global trends in the affordability of the most sold brand of cigarettes also describe the changes in the affordability of brands of cigarettes in different market segments, in particular the cheapest and premium brand of cigarettes. Thus, the change in average affordability of the cheapest and premium brands of cigarettes between 2008 and 2018 were examined by income group to address this objective.

\section{Data sources}

The data used in this paper were taken from the biennial WHO Report on the Global Tobacco Epidemic (5). Data were collected for the report by WHO at country level over a period of 6 months, in the 18 months preceding the publication of the report (13). The cheapest, most sold and premium brands were identified and the retail prices of a pack of 20 sticks of these cigarettes were recorded from two types of retail shops in local currency units. The published data included the affordability index for the most sold brand of cigarettes (5). Using the same method as in the WHO report, the authors calculated the affordability of the cheapest and premium brands of cigarettes (5). GDP per capita data in local currency units was taken from the International Monetary Fund's World Economic Outlook database (14).

Country income groups were as defined by the World Bank in 2018 (15). However, the World Bank did not allocate an income group for Cook Islands in 2018. To classify Cook Islands, WHO applied the World Bank classification method using the most recent Gross National Income estimate from the United Nations Statistics division. All analysis was carried out by income groups as defined in 2018 to prevent comparisons capturing compositional effects of income groups, rather than the average of trends within countries in the period.

Due to missing GDP per capita, prices of the most sold brand of cigarettes data for 21 countries were excluded. Missing data on the price of the most sold brand of cigarettes meant that 4 countries were also excluded. Lack of data regarding the price of the cheapest or premium brand of cigarettes meant that 30 more countries were excluded. Sixteen countries were excluded due to inconsistencies in the data such as a higher price for the cheapest brand than the most sold brand, or cheaper price of the premium brand compared to the most sold brand. The remaining data set consisted of 125 countries. Since there were 13 low-income countries in this data set, and only one low-income country in the EMR, all low-income countries were excluded. The final sample consisted of 112 countries and included 13, 25, 16, 39, 3 and 16 countries from the Africa, Americas, Eastern Mediterranean, Europe, South-East Asia and Western Pacific regions, respectively.

\section{Affordability: percentage of GDP per capita needed to purchase 2000 sticks of the cheapest, most sold and premium brands of cigarettes}

Affordability is a measure of the ability of a person to buy a good (15). If income growth outpaces increase in prices then affordability increases. To examine the affordability of cigarettes in EMR countries compared to the rest of the world, a simple average of the affordability index was calculated per income group for EMR countries and for the rest of the world (excluding EMR countries). The results are shown with $95 \%$ confidence intervals. Affordability tends to be lower in higher income countries, and therefore affordability is examined by income group so that results are not driven by this phenomenon (2).

\section{Results}

\section{Affordability of the cheapest, most sold and premium brands of cigarettes in EMR compared to the rest of the world by income group (Figure 1).}

Historically, cigarettes in the EMR has been more affordable than cigarettes in the rest of the world. Although this pattern is lessening, it still largely persists. In 2008, the cheapest, most sold and premium brands of cigarettes in the EMR were on average more affordable than in the rest of the world in lower-middle, upper-middle and high-income countries. The difference between the affordability of the cigarettes in EMR countries and the rest of the world, for all three brands, was largest in lower-middle income countries, where it took as much as $3.95 \%$ more of GDP per capita to buy the premium brand of cigarettes on average in the rest of the world compared to the EMR. Only the difference between the affordability of cigarettes in high-income countries between EMR countries and high-income countries in the rest of the world was statistically significant at the $5 \%$ level. Brands of cigarettes in high-income countries of the EMR cost individuals between $1.16 \%$ and $1.41 \%$ less of GDP per capita to purchase compared to individuals in high-income countries in the rest of the world. 
In 2018, this pattern persisted across brands and income groups, apart from the premium brand of cigarettes in upper middle-income countries, which were less affordable in EMR countries compared to upper middle-income countries in the rest of the world. An individual in upper middle-income countries of the EMR spent on average around 1.79\% of GDP per capita more to buy a pack of premium brand cigarettes than a similar individual buying the premium brand in another uppermiddle income country in the rest of the world. The only significant difference in affordability between the EMR and the rest of the world was in regards to the most sold brand in high-income countries, which cost on average $0.85 \%$ of GDP per capita less in EMR compared to highincome countries in the rest of the world.

Between 2008 and 2018, there was a convergence between the affordability of cigarettes in the EMR and in the rest of the world. Cigarette brands in EMR countries became on average between $0.06 \%$ to $1.17 \%$ of GDP per capita closer to the affordability of brands in the rest of the world.

In lower-middle income countries in the EMR, all the studied brands converged towards the affordability of these brands in lower-middle income countries in the rest of the world, especially the cheapest and premium brands.

In upper-middle and high-income countries the affordability of the most sold and premium brands of cigarettes converged towards the affordability of these brands in corresponding countries in the rest of the world. However, the affordability of the cheapest brand of cigarettes in upper-middle and high-income countries in the EMR diverged further from the affordability of these cigarettes in upper-middle and high-income countries in the rest of the world by $0.28 \%$ and $0.35 \%$ of GDP per capita respectively.

\section{Global trends in the affordability of the cheapest and premium brand of cigarettes (Figure 1).}

Globally, in upper-middle and high-income countries the affordability of the cheapest and premium brand of cigarettes is decreasing. The decrease in the affordability of the premium brand of cigarettes in high-income countries in the EMR of $1.02 \%$ of GDP per capita is significant at the $5 \%$ level.

In lower-middle income countries worldwide the premium brand of cigarettes are becoming more affordable and the cheapest brand of cigarette are becoming less affordable.

\section{Discussion}

In 2008, cigarettes in the EMR were more affordable than in the rest of the world and this pattern persisted in 2018, despite convergence of the affordability of cigarettes in the EMR towards the affordability of cigarettes in the rest of the world. This historic and persisting relative affordability of cigarettes in the EMR compared to the rest of the world could offer explanation to the current and predicted increase in tobacco smoking among males aged 15 years or older from the Region (4). The significant decrease in the affordability of the most sold brand of cigarettes in high-income countries of the EMR is likely due to implementation of the Gulf Cooperation Council (GCC) countries' excise tax on tobacco products (5).

The affordability of the cheapest and premium brand of cigarettes has decreased in upper-middle and high income countries and increased in lower-middle income countries globally. This shows the same pattern as the trend in the affordability of the most sold brand of cigarettes identified in the literature, suggesting that this trend is seen across market segments of the cigarette market.

\section{Limitations}

There are two main limitations to the analysis due to a lack of available data. Firstly, this research examined the affordability of the cheapest, most sold and premium brand of cigarettes in each country. Measures used should capture broad market dynamics. While using changes in affordability of three brands in each country is better than only examining one, this remains an issue. Ideally, examining a measure such as the weighted average price would allow a more comprehensive understanding of the market dynamics. Secondly, the affordability index used was the percentage of GDP per capita needed to purchase 2000 sticks of the chosen brand of cigarettes. Some research has defended the use of GDP per capita as a denominator, in particular in lower-middle income countries where there may be increased reliance on state provision, and so GDP per capita is more reflective than individual income levels (10). There is a strong case that the denominator of an affordability index should be individual income levels or wages. This would better reflect the consumption decisions faced by individuals. However, the data necessary for this index were less readily available on a global scale.

\section{Conclusion}

This research finds evidence that cigarettes in the EMR have been historically more affordable than in the rest of the world, and this trend continues despite some convergence between the affordability of cigarettes in the EMR and the rest of the world. This may offer explanation to the current and predicted increases in the use of smoking tobacco products among males in the Region (4).

The implementation of Article 6 of the FCTC should be a priority in the Region in order to reduce the affordability of cigarettes in the EMR compared to the rest of the world. This will act to decrease the prevalence of smoking and health and economic burdens of cigarettes. It is worth noting that effective implementation of Article 6 of the WHO FCTC must include actions to strengthen tax administration. While the risk of increased illicit trade following increases in tax is overstated by the tobacco industry, it is a factor that must be considered. Countries that have simultaneously strengthened tax 


\section{Lower-Middle income}

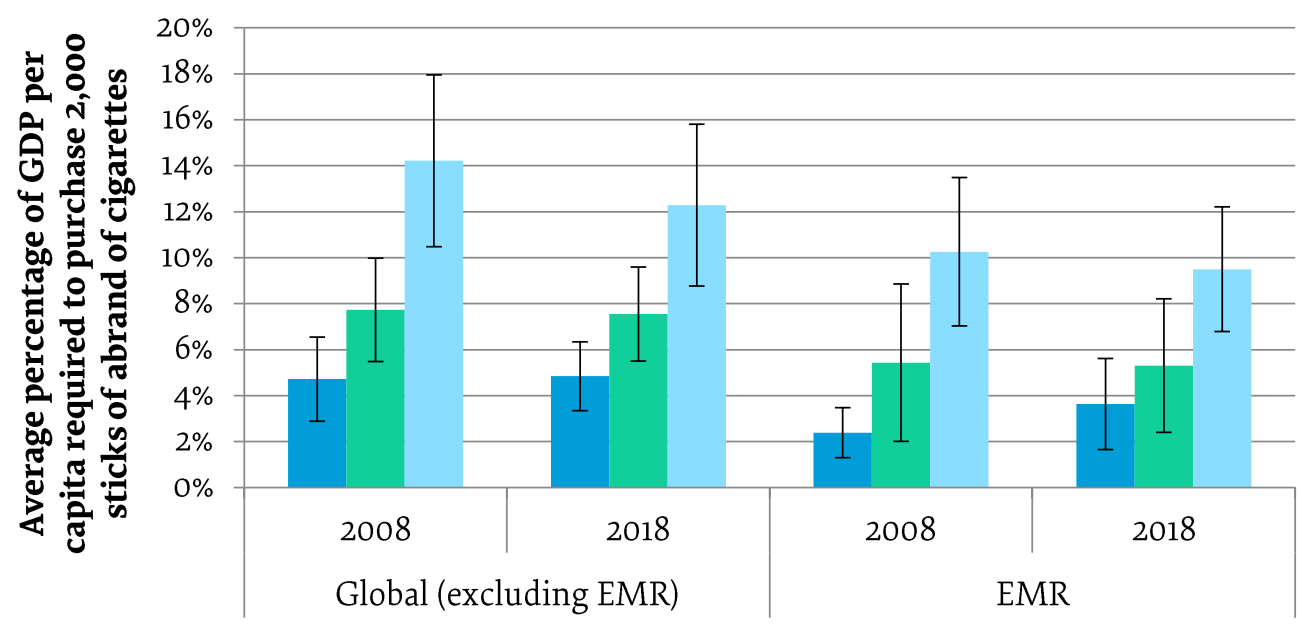

- Cheapest

- Most sold

Premium

\section{Upper-Middle Income}

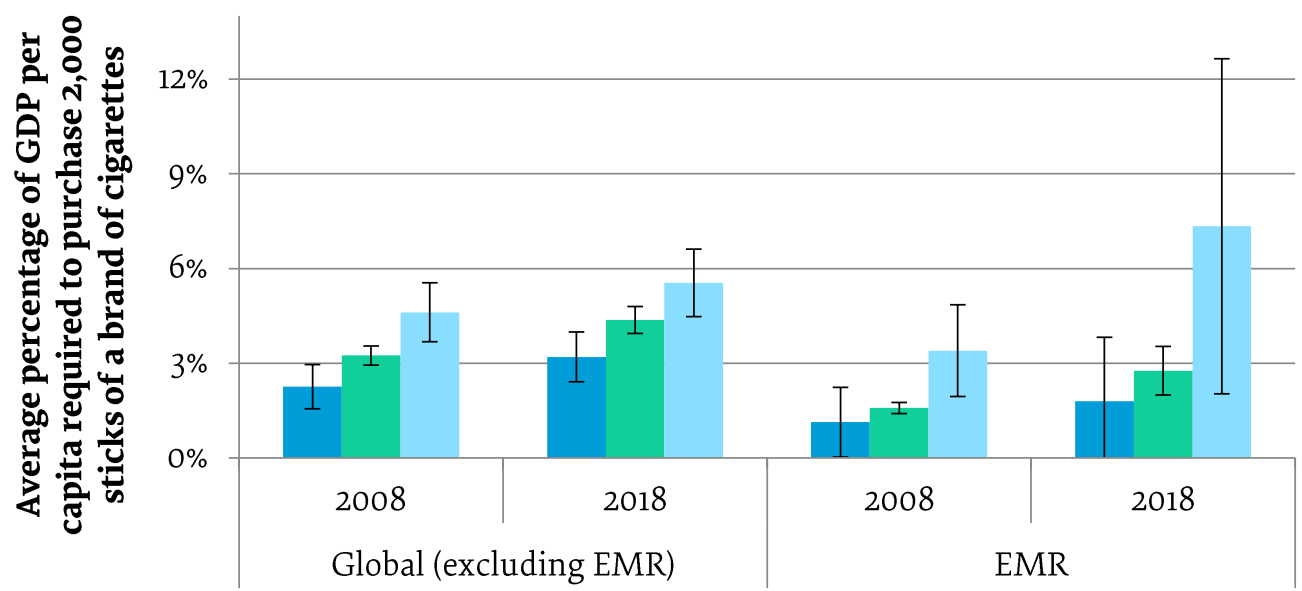

Cheapest

Most sold

Premium

High Income

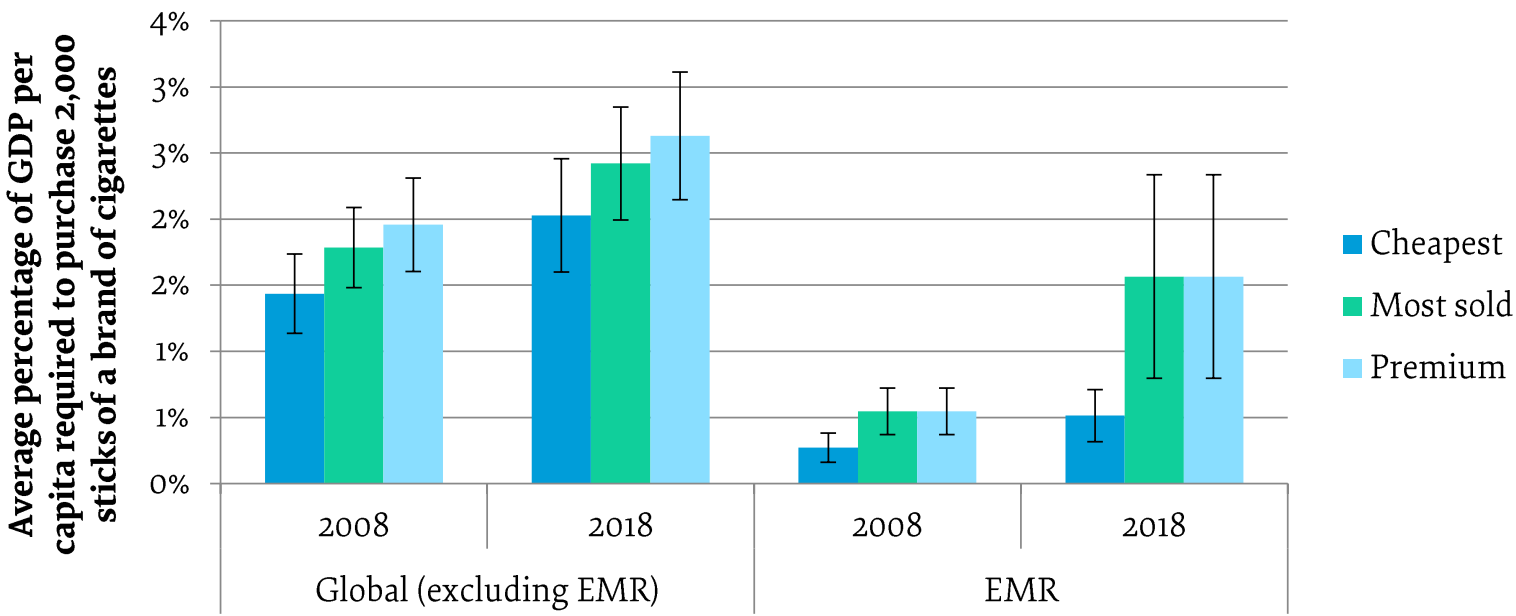


administration and increased tobacco taxation have seen increased tax revenue, increased tobacco prices and decreased tobacco consumption.
Funding: None.

Competing interests: None declared.

\section{Accessibilité économique de la cigarette dans la Région de la Méditerranée orientale Résumé}

Contexte : La Région de la Méditerranée orientale de l'Organisation mondiale de la Santé est la seule région de l'OMS où l'on observe et prévoit une augmentation de la prévalence des produits du tabac à fumer chez l'homme. Il n'y a pas d'analyse régionale de l'accessibilité économique des cigarettes dans la littérature.

Objectifs : La présente étude visait à comparer l'accessibilité économique des marques de cigarettes les moins chères, les plus vendues et les plus haut de gamme entre les pays de la Région de la Méditerranée orientale et les pays du reste du monde, par groupe de revenus, en 2008 et 2018.

Méthodes : L'accessibilité économique a été définie comme le pourcentage du PIB par habitant nécessaire pour acheter 2000 cigarettes. Une moyenne simple et un intervalle de confiance à 95\% pour l'accessibilité économique ont été calculés par groupe de revenu pour les pays de la zone de la Région de la Méditerranée orientale et pour le reste du monde.

Résultats: Historiquement, les marques de cigarettes les moins chères, les plus vendues et les plus haut de gamme étaient en moyenne plus économiquement abordables dans la Région de la Méditerranée orientale par rapport aux mêmes marques dans le reste du monde, et ce dans toutes les catégories de revenus. Ce schéma persiste malgré une certaine convergence entre l'accessibilité économique des cigarettes dans la Région et dans les pays du reste du monde. Conclusions : Le fait que les cigarettes demeurent plus économiquement abordables de tout temps dans la Région de la Méditerranée orientale par rapport au reste du monde pourrait expliquer les tendances de la prévalence du tabagisme dans cette Région. Il est nécessaire de poursuivre la mise en œuvre de l'article 6 de la Convention-cadre de l'OMS pour la lutte antitabac.

$$
\begin{aligned}
& \text { القدرة على شر اء السجائر في إقليم شرق المتوسط } \\
& \text { ميريام جوردن، آن-ماري بيروسيتش، روبرت توتانيس } \\
& \text { الخالاصة ميرم }
\end{aligned}
$$

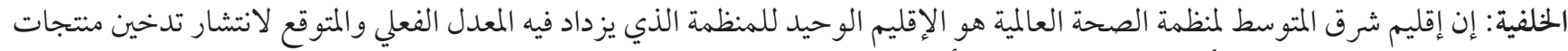

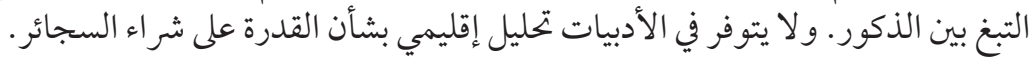

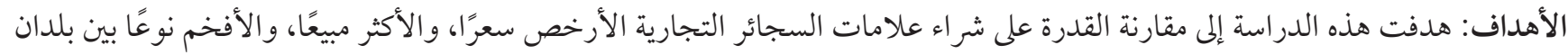

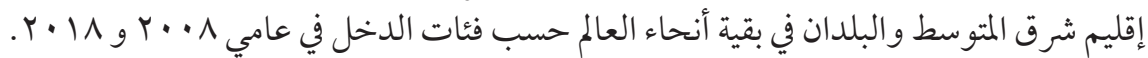

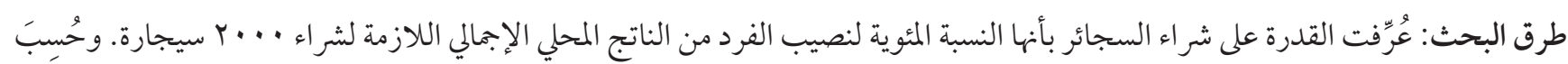

$$
\begin{aligned}
& \text { المتوسط البسيط وفترة الثقة } 90 \text { ٪ للقدرة على الشر اء حسب فئ فئات الدخل في بلدان إقليم شرق المتوسط وبقية العالم. } \\
& \text { النتائج: كان طو ال هذه الفترة متوسط أسعار السجائر الأرخص سعرًا والأكثر مبيعًا والأفخر نوعًا في متناول اليد في إقليم شرق المتوسط مقار مقارنةً }
\end{aligned}
$$

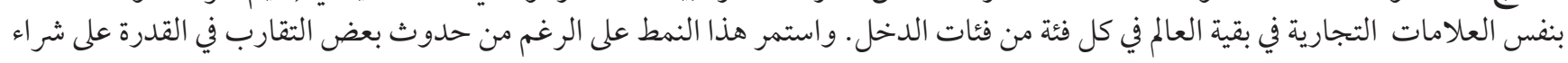

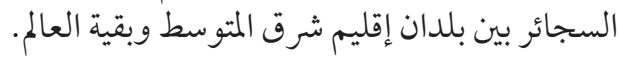

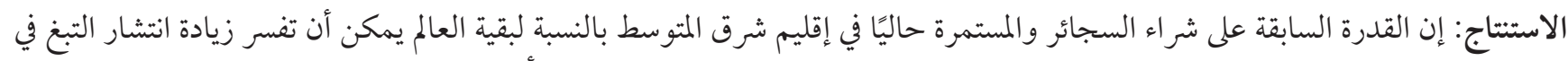

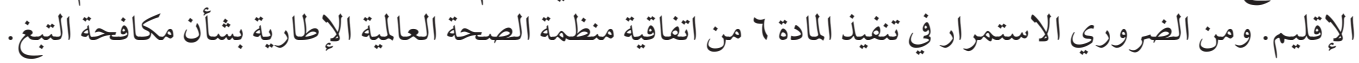




\section{References}

1. Stanaway J, Afshin A, Gakidou E, Lim SS, Abate D, Abate KH, et al. Global, regional, and national comparative risk assessment of 84 behavioural, environmental and occupational, and metabolic risks or clusters of risks for 195 countries and territories, 1990-2017: a systematic analysis for the Global Burden of Disease Study 2017. The Lancet. 2018;392(10159):1923-1994.

2. U.S. National Cancer Institute and World Health Organization. The economics of tobacco and Tobacco control. National Cancer Institute Tobacco Control Monograph 21. Bethesda, MD: U.S. Department of Health and Human Services, National Institutes of Health, National Cancer Institute; and Geneva: World Health Organization; 2016.

3. World Health Organization Regional Office for the Eastern Mediterranean (WHO/EMRO).About us. Cairo: WHO/EMRO; 2019 (http://www.emro.who.int/entity/about-us/index.html)

4. World Health Organization. WHO global report on trends in prevalence of tobacco smoking 2000-2025. Second edition. Geneva: World Health Organization; 2018.

5. World Health Organization. Report on the global tobacco epidemic, 2019. Geneva: World Health Organization; 2019.

6. Guidelines for the implementation of Article 6 of the WHO FCTC. Price and tax measures to reduce the demand for tobacco. Geneva: World Health Organization; 2017 (https://www.who.int/fctc/guidelines/adopted/Guidelines_article_6.pdf)

7. Verguet S, Gauvreau CL, Mishra S, MacLennan M, Murphy SM, Brouwer ED, et al. The consequences of tobacco tax on household health and finances in rich and poor smokers in China: an extended cost-effectiveness analysis. The Lancet Global Health. 2015;3(4):206-216.

8. Salti N, Brouwer E, Verguet S. The health, financial and distributional consequences of increases in the tobacco excise tax among smokers in Lebanon. Soc Sci Med. 2016;170:161-169.

9. Sassi F, Belloni A, Mirelman AJ, Suhrcke M, Thomas A, Salti N, et al. Equity impacts of price policies to promote healthy behaviours. The Lancet. 2018;391(10134):2059-2070.

10. Blecher. E. Targeting the affordability of cigarettes: a new benchmark for taxation policy in low-income and-middle-income countries. Tob Control. 2010;19:325-330.

11. Blecher E, van Walbeek C. An analysis of cigarette affordability. Paris: International Union Against Tuberculosis and Lung Disease; 2008.

12. He Y, Shang C, Chaloupka FJ. The association between cigarette affordability and consumption. bioRxiv preprint; 2018 https:// doi.org/10.1101/361287.

13. World Health Organization. Technical note III: Tobacco taxes in WHO Member States. Report on the global tobacco epidemic, 2019. Geneva: World Health Organization; 2019.

14. International Monetary Fund. World Economic Outlook Database. Washington, DC: International Monetary fund; 2019 (https:// www.imf.org/external/pubs/ft/weo/2019/01/weodata/index.aspx)

15. Blecher EH, van Walbeek CP. An international analysis of cigarette affordability. Tob Control. 2004;13:339-346. 